\title{
Child Safety Issues in Cyberspace: A Critical Theory on Trends and Challenges in the ASEAN Region
}

\author{
A.R. Mubarak \\ Senior Lecturer \\ Department of social work \\ Flinders University \\ Adelaide SA5001
}

\begin{abstract}
The Internet has revolutionised the ways in which people interact and access information. While a majority of the contents found in cyberspace are useful and beneficial to communities, there are some which are not suitable for children and adolescents. Specifically, contents that are suitable only for adults can be easily accessed by children. This poses a significant challenge to children's normal development. Further, individuals, groups and organisations have misused certain cyberspace facilities, such as social interaction websites and online game sites, to specifically target children and abuse and harm them. Police and other law making authorities are seriously challenged by rapidly developing Internet technology and newly emerging techniques in which anti-social elements target children. Communities living in the Association of South East Asian Nations (ASEAN) region are no exception to these challenges. This paper using critical theory analyses the cyber challenges faced by children in this region and suggests ways in which policy makers can take firm steps to protect them to ensure their safety and maximise the benefits of online contents.
\end{abstract}

\section{General Terms}

Online child safety in ASEAN region, Child abuse in ASEAN countries, Cyber laws in Asia.

\section{Keywords}

Cyberspace, Child safety, Policy making, Community development, ASEAN, critical theory

\section{INTRODUCTION}

Cyberspace has created endless opportunities for humanity. A few decades ago, many segments of the population, particularly ethnic and minority communities living in remote parts of the world, could not imagine connecting themselves with the wider world and becoming active members of the global community. In recent years, Information and Communication Technology (ICT) has helped these population groups connect with mainstream communities and enjoy their fair share of development and prosperity. Economic analysis indicates that ICT has served as a key catalyst for growth and productivity in many countries. As a result, governments have shown a keen interest in investing in IT infrastructure developments and encouraging their populations to use ICT tools. In the 1990s, Kraemer and Dedrick (1994) observed a close and significant association between the level of IT infrastructure development and economic growth. This trend has resulted in a significant increase in the use of ICT tools by populations around the globe and countries within the Association of South East Asian Association Nations (ASEAN) are not an exception to this. Accordingly, Kraemer and Dedrick (1994) predicted a positive relationship between IT infrastructure expenses and productivity and economic growth in 12 Asia Pacific countries. Use of ICT tools has grown rapidly in this region in recent years and is forecast to multiply even faster due to the increase in the region's population of young people. The ICT use rate in the ASEAN region was predicted to grow by $10900 \%$ in Myanmar from a $0.21 \%$ base rate and $12034 \%$ in Vietnam by the year 2010 (Internet World Stats 2014). Brunei Darussalam had the highest Internet access rate, with $80.73 \%$ of the population connected.

While this ICT revolution has advantaged many segments of ASEAN populations, it has challenged other segments. One such population group is children who, no matter where they are in the world, can become part of the world-wide trend of engaging in highly risky behaviour while using ICT tools. Such behaviour includes accessing inappropriate materials that are suitable only for adults, interacting with adults such as paedophiles, becoming victims of exploitation by adults, accessing pornography, and knowingly or unknowingly engaging in child prostitution and child trafficking. The ASEAN region has a population of over 600 million and this number is growing very fast. Internet users in ASEAN region have doubled and a report by ILO notes that ICT and increasing use of the Internet has created new opportunities for offenders to facilitate their criminal behaviours (ILO 2014). Especially, children have been found to be increasingly at risk of harm by technological revolutions happening in mobile phone and internet technologies. In the past, the Internet and mobile phones were separate entities and children could access the Internet only through personal computers, where parents or teachers could easily supervise Internet use. The recent convergence of mobile phones and Internet access has rapidly increased the number of young people using the Internet with minimal or no parental supervision. While this technological convergence has resulted in easy access to the internet linking many communities including the ones located in remote regions of ASEAN to the World Wide Web benefiting them enormously, vulnerable groups such as women and children could be targeted by anti-social elements if the internet is not used cautiously. This paper will discuss the ways in which ICT revolution within ASEAN countries have increased the vulnerability of children and exposed them to dangers which were never envisaged in the past. This paper will discuss the ways in which ICT revolution within ASEAN countries have increased the vulnerability of children and exposed them to dangers which were never envisaged in the past. Using information collected through secondary sources the present paper argues that newly emerging tech savvy cybercrimes involving children have created an urgency for ASEAN communities and nations to unite in a creative effort to reform their approach to child safety in cyberspace. 
Critical theory was used as a framework for conducting this research on child safety issues in the ASEAN region. Critical theory was originally developed in the 1920s at the Institute of Social Research at the University of Frankfurt. At the earlier stages, this theory had a significant influence of Marx and George Lukac's History and Class Consciousness through the writings of pioneer critical theorists such as Horkheimer, Adorno and Marcuse. However, after the Word Wars, in the late 1960s and early 1970s, the writings of an influential critical theorist, Jurgen Habermas, significantly reduced the Marxian influence on critical theory. Through its criticism of orthodox Marxism, Habermas widened the scope of critical theory far beyond the class interest of Marx's theory to include day-to-day societal issues such as culture, family, sexuality, science, etc. (Ray, 1990). This significantly broadened the subject matter of critical theory. In recent years critical theory has aimed to achieve a just, rational, humane and reconciled society through critical analysis of the social and political environments prevailing in society. The subject matter covered by the critical theory has been significantly wide in the recent years. It has been dealing with a range of issues such as government policies, attitudes of individuals and groups, discrimination and rights of the oppressed, and challenges related to the creation of social balance between the personal autonomy of individuals and the universal solidarity of collectives (Agger, 2006). As a result, critical theory gained much popularity as a critique of authority and capitalism and a friend of those who are victims of oppression and discrimination.

As a major critique of authority and due to its orientation towards critically analysing the issues related to loop holes in policy making and policy implementation and oppression and discrimination by Governments and policy makers, critical theory provides an efficient framework for reviewing the ASEAN region's child safety issues in cyberspace. Further, child safety issue in cyberspace is a broad concept touching all layers of society - from government to internet service providers to individuals. Each layer consists of institutions, leaders with their mind-set and attitudes and individuals with mentalities and practices and reveals their impact on the society (Centre for social and political thought, 2015). Using critical theory the present research aimed to critically review child safety issues of ASEAN children in cyberspace. Critical theory attempts not only to understand society, but also to diagnose and treat its dysfunctions. Hence, based on the findings of the critical review, an attempt will be made to propose appropriate solutions to the problem areas identified by the review process. In his methodological writings Hebermas' strategy is always that of 'concrete negation'. He measures the concept under investigation against its own claims of strengths and brings out the limitations to specify in which situations, in what ways, and to what ends this particular concept might be employed (McCarthy, 1978). The same method will be used in the present research. The child safety policies of ASEAN countries and their implementation will be critically evaluated against their own aims and objectives and the level of success as claimed by the policy or policy making body. Yet another important component of this review will be to highlight the extent to which ASEAN children are treated with justice and fairness. Sustenance and autonomy of individuals and groups in the society are the ultimate aim of critical theory and the same will be highlighted in this critical analysis whenever it is required.

\section{ICT TOOLS AND CHILD SAFETY ISSUES IN THE ASEAN REGION}

Since the late 2000s, member countries within the ASEAN region have seen a rapid increase in ICT use by its population. For example, it is estimated that $38 \%$ of ASEAN population will be broadband subscribers in 2015 when compared to $1 \%$ in 2009 . Similarly, 10 ASEAN countries advertise their internet speed as above $2 \mathrm{Mbps}$ when compared to only 6 countries in 2009 (Yuwono 2014). This technological trend in ASEAN region has also helped children in this region to have easy access to the internet technology. During the earlier part of this technological revolution, tools such as instant messaging, chat rooms and online games gained rapid popularity among ASEAN communities. There was optimism that Internet technology would empower children and other weaker sections of the communities because of its capacity to reach population groups living in remote and disadvantaged geographic and socio-economic conditions (Mehra, Merkel and Bishop 2004). While the Internet did succeed in empowering many communities through its global reach, it also exposed ASEAN region's children to many unforeseen dangers. The World Wide Web contained much material that was not suitable for children and opened the door to online child exploitation. The following discussion highlights some of the more extreme dangers.

\section{CHILDREN'S ACCESS TO SEXUAL IMAGES AND PORNOGRAPHY}

Young people exposed to sexually explicit and pornographic images may develop unrealistic and unhealthy sexual expectations (Owens et al. 2012). Traditionally, communities living in the ASEAN region had their own unique cultural practices that prepared their young adults for a sex life within culturally accepted norms. These highly supervised practices, firmly based in community priorities for the welfare of the child, were passed down from one generation to another. Unfortunately, the Internet has changed this tradition and ASEAN children who are exposed to online sexual and pornographic materials at a very young age run a high risk of developing understandings of sex and its role in intimate relationships that do not fit within their cultural practices. Pornography often depicts gender-biased violence and unnatural expectations from sexual activities. Children look upon these sexual acts as role models and may therefore engage in risky sexual acts. For example, in Cambodia, two teenage boys were reported to have raped a seven year old girl after watching a pornographic video (Phnom Penh Post 2012).

While children in developed countries access the Internet at home, which helps to limit their exposure to unwanted sites, in developing countries children often use public venues such as Internet cafés where there is no parental supervision. Internet cafés can be dangerous places for children due to their layout, which often provides dark and private spaces with Internet users sitting in close proximity, providing the perfect opportunity for adults to sexually abuse children. A survey from Thailand suggests that $35 \%$ of participating 7 11 year olds reported watching websites displaying pornographic images (Michelet 2013), clearly highlighting the increasing vulnerability of ASEAN children. This statistic demonstrates the need for community leaders and policy makers to take action. Sadly, in many countries, both developed and developing, there is no legislation regulating children's use of the internet (Protection of minors 2014). 


\section{SOCIAL NETWORKING SITES AND CHILD GROOMING}

Use of social networking sites has seen exponential growth in the ASEAN region. For example, Indonesia had 48 million Facebook users and the Philippines had 30 million in January 2013 (Statista 2015) and it is estimated that Facebook has 120 million of ASEAN population and Indonesia, the Phillipines, Thailand and Malaysia are among the 22 largest Facebook communities in the world (ASEAN 2015a). These figures highlighting the potential for exposing children to strangers online and posing yet another challenge to children and young people in the ASEAN region. Unfortunately, social networking sites have no restrictions on access and curious young people, pretending to be adults, can become exposed to anti-social elements such as child traffickers and paedophiles; they are innocent prey for such cyber criminals. Conversely, paedophiles can pretend to be other children and become close cyber friends with their victims. Child sex offenders groom the children online to gain their trust then sexually exploit them, resulting in significant damage to childhood development. Worse still, some children are trafficked after the grooming is complete. For example, online social media allows for new ways to facilitate people trafficking, distribution of child abuse material and new avenues for recruiting victims. It is estimated that nearly one quarter of children reported missing in Indonesia are thought to have been lured into trafficking by their captors, who recruited them through Facebook (MTV Exit 2014).

Recently, online interactive game sites introduced chat facilities, a move that has significantly increased children's use of chat rooms. Michelet's (2013) survey of 7-11 year olds in Thailand reveals that $24 \%$ of respondents reported meeting face-to-face with someone they met online and 58\% of these respondents reported unpleasant experiences during the meeting.

\section{USING MOBILE PHONE CAMERAS FOR INAPPROPRIATE PURPOSES AND ONLINE GAMBLING BY CHILDREN}

The combination of mobile phones and Internet technology has removed all restrictions on Internet access, even for children living in the lowest socioeconomic ASEAN regions. It is estimated that Smartphone sales have been estimated to grow in Vietnam, Indonesia and Thailand at a compound annual growth rate of $37 \%, 31 \%$ and $27 \%$ respectively from 2011 through to 2016 (Accenture 2014). In Indonesia, 12 is the most common age for children to own a mobile phone and $54 \%$ of children who use mobile phones use them to access the Internet (GSMA NTT DOCOMO 2012). This increasing Internet use through mobile phones has introduced many new challenges, such as taking photos of other children without consent and circulating them through online forums such as social networking sites. There are numerous reports of children using mobile phone cameras to film girls and boys engaged in sexually explicit activities or sexually explicit poses, and circulating the images among friends.

In countries in the ASEAN region that have a huge sex industry, particularly in terms of sexual tourism (Tanielian 2013), child sex predators are looking for soft targets. Sexual images of children on the Internet can be misused to blackmail and harm innocent children. Sexting (sending sexual images of oneself or others via mobile phone) can not only cause serious damage to young people's reputations but explicit images can easily fall into the wrong hands, for example pornography companies. If this happens, children may be exposed to long term psychological trauma.

Easy access to online gambling is another challenge young people face due to the combination of Internet and mobile phone technologies. Many phones have 'apps' with games that can 'normalise' gambling attitudes in children and teenagers. The boundary between gambling and usual games is very thin and can become blurred, heightening the risk of pushing children into gambling. Significantly, gambling has cultural origins in many Asian communities (Raylu and Oei 2004). It has been an approved leisure activity for adults and a traditional part of family and community activity during festive occasions. Until recently, gambling was predominantly limited to adults but online casinos, which can be accessed easily through mobile phones, has opened it up to children. Unknown to their parents, children may be participating in online gambling and possibly losing significant amounts of money, resulting in extreme stress and other mental health problems. Reliable data on the extent to which ASEAN children lose money through online gambling is not available at the time of writing this paper.

\section{ONLINE GAMES}

Online games are very popular among children globally. Millions of children, particularly adolescents, have been playing these games $24 / 7$. In order to increase their customer base, the corporations designing these games have significantly increased rewards for regular users. Some companies have introduced many types of creative rewards, such as tokens for high achievers, which can be traded for money. This has increased the vulnerability of children and particularly those living in regions with limited job opportunities, such as ASEAN countries. Recent studies have reported these games as having a high potential to create psychological addiction among users (Griffiths 2010). This has emerged as a potential public health concern. In Thailand, for example, nearly 3 million children have been estimated as being addicted to online games in Thailand (Thai PBS 2014).

\section{ONLINE PROSTITUTION AND THE PRODUCTION AND DISTRIBUTION OF CHILD PORNOGRAPHY}

The ICT creation and distribution of child sexual abuse and exploitation is another major cybercrime challenging children worldwide but particularly children living in the ASEAN region. Easily accessible Internet, cheaply available digital cameras and cameras built into mobile phones have dramatically reduced the cost of production and distribution of child pornography. By the year 2000, Interpol (international police force) had collected evidence of possession and distribution of hundreds of thousands of images involving child sexual abuse (Carr 2004). ASEAN communities have been seriously affected by a rapid increase in the local production of child pornography for distribution to other countries.

Even more disturbing is the Internet facilitation of live child prostitution and child pornography using web cameras. Audiences for these live shows log on from all over the world and reward the children by paying money. In the Philippines, for example, children perform sexual acts in 
front of web cameras as instructed by a viewer who pays for the particular acts (Trinidad 2005). Online child prostitution and pornography prey on poverty stricken children's high vulnerability and lack of awareness that their sexual images will remain in cyberspace forever. Perpetrators lure poor parents to sell their children to prostitution rings. These child prostitutes then become helpless targets for paedophiles.

\section{ONLINE PROSTITUTION AND THE PRODUCTION AND DISTRIBUTION OF CHILD PORNOGRAPHY}

The ICT creation and distribution of child sexual abuse and exploitation is another major cybercrime challenging children worldwide but particularly children living in the ASEAN region. Easily accessible Internet, cheaply available digital cameras and cameras built into mobile phones have dramatically reduced the cost of production and distribution of child pornography. By the year 2000, Interpol (international police force) had collected evidence of possession and distribution of hundreds of thousands of images involving child sexual abuse (Carr 2004). ASEAN communities have been seriously affected by a rapid increase in the local production of child pornography for distribution to other countries.

Even more disturbing is the Internet facilitation of live child prostitution and child pornography using web cameras. Audiences for these live shows log on from all over the world and reward the children by paying money. In the Philippines, for example, children perform sexual acts in front of web cameras as instructed by a viewer who pays for the particular acts (Trinidad 2005). Online child prostitution and pornography prey on poverty stricken children's high vulnerability and lack of awareness that their sexual images will remain in cyberspace forever. Perpetrators lure poor parents to sell their children to prostitution rings. These child prostitutes then become helpless targets for paedophiles.

\section{CYBER BULLYING}

A culture of bullying using ICT has emerged as a challenge to children worldwide. Usually, children use many media such as emails, phone text messages, chat rooms and social networking sites to bully other children they perceive as weak and vulnerable. The worst aspect of cyber-bullying is that the person engaging in bullying can choose to remain anonymous, thus complicating the process by enabling longterm perpetration with the victim having no means to identify them. Further, due to anonymity and the victim's remote location, the person engaging in bullying does not see the direct effect of their actions on their victims, which facilitates increased severity of the bullying. Cyber bullying has become common among ASEAN children due to increased use of mobile phones. Melatdouse (2014) identified that as of 2007, 60 cases of cyber-bullying were reported to Malaysia's CyberSecurity team while in Singapore 80 cases were reported to WiredSafety, an online safety and assistance team. Similarly, in Thailand, a survey conducted among 2500 children indicated that $43.1 \%$ of participating children had experienced cyber-bullying (Wisdom Society for Public Opinion Research 2010). Cyberbullying is another serious challenge arising from the ICT revolution and requires urgent action by ASEAN policy makers and community leaders to safeguard children and adolescents. In 2015 Singapore parliament has passed a new law under which anti-social acts such as cyber harassment, bullying of children, sexual harassment in the workplace and stalking are deemed illegal and punishable by jail term and fine up to $\$ 5000$ Singapore (The Diplomat 2015). Similar steps needs to be taken by other countries and a regional approach will strengthen the law enforcement process.

\section{THE NEED FOR REGIONAL INITIATIVES TO SAVE CHILDREN IN CYBERSPACE - IMPLICATIONS FOR ASEAN COUNTRIES}

Analysis of factors related to the issue of ASEAN children's safety in cyberspace has identified poverty, disempowerment and lack of resources placing families and communities in a weak position to fight against crimes in the form of exploitation of children (Akaha 2009). Loop holes in policy making and widespread innate corruption in some countries in the ASEAN region make it a difficult task to overcome the problem (Tanielian 2013). Also, cyberspace reaches beyond each country's territorial borders and legal jurisdiction, raising the question of who has the authority to bring cyber-criminals to justice if it is possible to find out who they are? For example, criminals living anywhere in the world can easily exchange information related to secret locations within the ASEAN region where opportunities exist for criminal and exploitative activities. Worse still, the criminal activities perpetrated by one criminal can be instantly shared among members of criminal rings worldwide, increasing the severity of the damage to victims. Technologies such as file sharing between computers have the capability of sharing thousands of images without the knowledge of any third party (Center for problem-oriented policing 2015).

Recently, paedophile rings have embraced advanced technologies that help them to actively engage in criminal activities involving children and to spread their activities beyond national borders. Loopholes in law making and law enforcement in one country can be shared among criminals. Unless the country concerned is extremely quick to learn this loophole and rectify it, the criminals remain one step ahead and can easily subject vulnerable target groups such as children to ongoing exploitation. Thus, recent advancements in ICT have complicated the law making process worldwide (Rogers 2013) and ASEAN region has come under extreme pressure to rethink their legal framework as a region through the necessity to redefine cyber-criminal behaviour and the jurisdiction of criminal behaviour, and constantly update the criminal justice and legal prosecution systems.

Countries worldwide have created a variety of new global and regional collaborations between law making and law enforcement authorities. One major milestone in this direction is the formation of the 'United Nations Convention against Transnational Crime', which has helped countries cope with the global nature of criminal behaviour in cyberspace (United Nations 2000). In the year 2003, the United Nations passed a draft resolution on cyber-security and the protection of critical information infrastructures, which invited countries and all relevant organisations to cooperate through sharing information related to cybercrime. Another major milestone is the formation of the Council of Europe's 'Cyber-crime Convention' which initiated a regional mechanism among European countries to fight cyber-crime (Coucil of Europe 2015). Since then, many regional bodies such as Interpol, The Organisation of American States, The Asia Pacific Economic Council and ASEAN have initiated regional initiatives to fight against criminal acts against children in cyberspace. ASEAN 
recognised the threat of cybercrime in the region and in 2014 established the ASEAN Senior Officials Meeting on Transnational Crime (SOMTC) (ASEAN 2014). While in some ways these initiatives have proved effective in protecting children in cyberspace, they have faced their own internal differences due to cultural diversity and differences in opinions among member countries.

Member countries of ASEAN as a regional body started taking a few key steps to prepare themselves to deal with the challenges posed by the ICT revolution in the late 1990s. In 1998, the leaders of ASEAN met in Hanoi and proposed the establishment of a joint body known as ASEAN Information Infrastructure (AII). As a part of this initiative, it was proposed that member countries would work towards standardisation of design, inter-connection and interoperability of IT systems by 2001. This resulted in the formation of e-ASEAN to link all ASEAN member countries as well as linking them to global telecommunications infrastructure. It sought to harmonise policies, regulations and standards related to member countries' information and communication technology tools (e-ASEAN 2015). When this initiative was launched, ASEAN countries faced new challenges such as lack of IT skills and the immediate need for radical changes in the mind sets of member countries' policy makers. In particular, it was realised that wide gaps in technological advancements between member countries could lead to even wider gaps in cooperation (Severino 2000). In spite of these challenges, it appeared that the formation of e-ASEAN helped member countries to acknowledge the urgent need for regional cooperation in order to survive in the digital age. However, a closer look at e-ASEAN's terms and conditions reveals member countries' narrow agenda to merely benefit from the economic advantages ICT can bring. The E-ASEAN framework Agreement states four objectives, namely, a) to develop, strengthen and enhance competitiveness of the ICT sector, b) reduce the digital divide within and amongst ASEAN member countries, c) promote cooperation between the public and private sectors, and d) develop ASEAN Information Infrastructure (ASEAN 2003). These objectives clearly prove that when e-ASEAN was formed, the member countries did not seem to realise the need for preparing to fight against the by-products of the digital revolution and its economic benefits. Issues such as child abuse and child exploitation in cyberspace were not recognised.

Since 1997, ASEAN countries have acknowledged the need for cross-border operations to curb criminal activities in the region. ASEAN has conducted a series of ministerial meetings and meetings of ASEAN National Chiefs of Police and formed a joint regional police body known as ASEANPOL (ASEANPOL 2015). In one of its SOMTC meetings in Singapore, ASEAN member countries highlighted the urgency of fighting against computer crime and reiterated the need for strong partnership between ASEAN and other international networks such as Interpol and the UN. Simultaneously, ASEAN member countries started making policy changes individually to incorporate cybercrime. However, these policies have not been coordinated among other member countries. For example, Thailand passed its Thai Cyber Law in 2007, which allowed police officers or other authorities to seize computers that were suspected of containing pornographic material or evidence of any cybercrime. This law applied to any computer in private premises. In 2015 the Thai Junta amended this Cyber Law which will grant the Thai Government unprecedented surveillance powers with little judicial oversight (Jakarta Post 2015). A similar move was implemented by Cambodia which passed its Cybercrime Law in 2014 (Kingdom of Cambodia 2014). Currently, Burma is in the process of introducing a new Electronic Transactions Law (The Irrawaddy 2015). While Laos has no formal cyber law, Laos Government has passed a new decree in 2014 which will impose stricter internet control in the country (Advocacy Global voice 2015). From these examples it is evident that the cyber space law enforcement is not uniform among the countries in ASEAN region.

\section{PROECTION FO ASEAN CHILDREN IN CYBERSPACE: THE WAY FORWARD}

In spite of the significant increase in vulnerability of ASEAN children in cyberspace and a concerted effort to promote cyber security in general among ASEAN's member countries, they are yet to adopt a region-wide policy on child protection issues such as production and distribution of child pornography, online child prostitution, children's use of internet cafés, child trafficking through online forums and other problems arising from uncontrolled Internet use. For example, ASEAN is yet to develop a region-wide uniform policy on the legal definition of production, dissemination, storage and use of materials involving sexual abuse of children. However, it is noteworthy that ASEAN is not the only regional body having this problem. It is reported that only 29 out of 187 countries that are members of Interpol have passed legislation to fight against child pornography and 93 countries have never passed such legislation (International Centre for missing and exploited children, child pornography 2008). Further, ASEAN member countries have some fundamental issues that increase the complexity of formulating and implementing standardised laws across the region. For example, the age of consent to have sex and the meaning of sexual relationships with children differs significantly due to different ASEAN countries' cultural and religious belief systems (UNESCO 2013). Some countries will allow adults to have sex with children as young as 13 years or even immediately after attaining puberty. For example, in Cambodia, 13 years is the age of consent to have sex whereas in Philippines it is 12 years and in Laos it is 15 years (Mahassni 2015). Criminals use this fundamental difference as a loophole to exploit children because it is easy for them to cross borders. Singaporeans, for example, are reportedly a major population group that will cross borders to Thailand and Indonesia to commit serious child sex offences (Williams et al. 2008)

The legal obligation of Internet Service Providers (ISP) to protect children in cyberspace is an area which needs specific mention. ISPs are major partners in crimes against children in cyberspace but their legal obligations are yet to be clearly defined in the ASEAN region. Many countries have introduced some regulations to guide the activities of ISP. For example, Singapore has adopted a policy where the Government decides what is acceptable content on-line and acts as a filter of internet content (Rao 2015). ISPs in the ASEAN region are yet to be obligated to identify the whereabouts of people who upload illegal images of children, or of businesses that operate child prostitute rings. It is time that the ASEAN region introduced legal obligations on the part of ISPs to ensure that materials passing through their network are legal, do not compromise the safety of children, and treat children with dignity and respect. 
Legal framework pertaining to children accessing mobile phones in the ASEAN region may need specific attention in terms of child protection issues. While most of the countries in this region have strict regulation pertaining to legal age to drink alcohol, similar legal framework is non-existent in many countries in this region to buy mobile phones. For example, minimum age to register for prepaid SIM card in Malaysia is 12 years (Malaysian communications and multimedia commission 2015). Further, it is time that the mobile companies had a legal obligation to educate their customers regarding safe use of mobile phones and the Internet. Installation of Internet filters can be one safe way of protecting children from accessing unwanted materials. While these filters are strongly encouraged by countries such as Singapore (Media development Authority of Singapore 2014), they are rarely used in a few countries in the ASEAN region. It will be beneficial if countries in the ASEAN region can unite together to obligate all ISPs in this region to install internet filters software for every customer at a minimum cost. Even more prudent would be a legal obligation for ISPs to monitor materials that are not suitable for children and either prevent uploading them or alert the families to materials that are not suitable for children.

The psychological issues pertaining to internet abuse such as cyber-bullying is a challenge that countries in the ASEAN region have started addressing in recent years. However, since cyber-bullying happens at child level, adults are not usually aware of it. Governments are no exception, seemingly turning a blind eye to the magnitude of the problem. While countries such as Malaysia and Singapore have launched nation-wide awareness campaigns other countries have not followed such as trend. May be financial constraints could be preventing some ASEAN Governments to follow the examples of Malaysia and Singapore. It is time for the ASEAN region to take cyber-bullying seriously and start pooling their resources to start a region-wide awareness campaign to reach children, families, schools and communities. Further, legal recognition of cyber-bullying is not uniform among ASEAN region countries. While Singapore passed a cyber-bullying law in 2014 (The Diplomat, 2015), some countries in this region do not even categorise cyber-bullying as an illegal act. Without criminalisation of cyber-bullying, it is extremely difficult to educate society about its seriousness.

Community capacity building has been a major challenge countries in ASEAN region have been experiencing for many decades. Extreme poverty and lack of education are the major hurdles for policy formulation and policy implementation in many ASEAN countries. Women and children as weaker sections of the community have been severely exploited due to poverty and corruption rampant in this region. Recently, the ASEAN Governments have united to form the Inter-government commission for human rights and the ASEAN commission on women and children (ASEAN 2015b). This project aims to develop the institutional capacity among the countries in this region. Such moves are positive and it is timely that the foundations of the societies are strengthened in order to empower the communities to fight against the negativities of the internet and to ensure that the members of the community make use of the internet in a safe environment and benefit from them.

\section{CONCLUSION}

The ASEAN region has long held the unpopular distinction of having one of the world's largest populations of child prostitutes. While the exact number of children exploited by the sex industry in the name of tourism promotion is not available (Tanielian 2013), ICT has further worsened the scenario. It is time that the countries in this region take a unified approach to protecting the children who are affected by exploitation in general and through cyberspace in particular. Children who have been psychologically and physically harmed by criminal acts need help to rehabilitate without stigma and criminalisation. There is a need for legislation to ensure this happens.

Since ASEAN is a body consisting of both rich and poor countries, it is time for the rich countries to realise their obligation to contribute to the welfare of children in poor countries and bridge the gap in child protection initiatives. This would lead to a healthy ASEAN with healthy citizens. Another challenge facing ASEAN countries is the cultural and economic diversity of this region, which challenges the implementation of joint initiatives. The economic gap between member countries in the region has long been recognised and acknowledged as a challenge. In 2014, the 'ASEAN Economic Community 'was launched as a step to bring some economic stability to the region. Older members of ASEAN, including Brunei, Indonesia, Malaysia, Philippines, Singapore and Thailand have stronger economies than more recently joined countries such as Cambodia, Laos, Myanmar and Vietnam. Among the member states, the smallest nations (Singapore and Brunei) have the most advanced economic growth, while Malaysia, Philippines, Indonesia and Thailand can be categorised in the medium development category. States such as Cambodia and Laos face many challenges due to widespread poverty. Finally, it is time for countries within ASEAN as a regional body to start taking firm and unified steps to protect their children in cyberspace. This can be achieved through a practical understanding of the vastness of cyberspace, and the urgent need for governments and communities to join hands to work together respectfully.

\section{REFERENCES}

[1] Accenture (2014). Surfing Southeast Asia's powerful digitalwave.http://www.accenture.com/Micros.http://w waccenture.com/Microsites/asiagoglobal/Documents/pd fs/page1/AccentureSurfingASENADigitalWaveSurvey. pdf.Accessed on 02 March 2015.

[2] Advocacy global voice (2015). Laos joins Southeast neighbours in imposing stricter internet controls, http://advocacy.globalvoicesonline.org/2014/09/28/laos joins-southeast-asian-neighborsinimposingstricterinternet-controls/accessed on 18 March 2015.

[3] ASEAN (2003). ASEAN telecommunications and IT ministers meeting (TELMIN), ASEAN secretariat news,

http://www.asean.org/communities/aseaneconomiccom munity/category/asean-telecommunicationsanditministers-meeting-telmin/accessed on 18 March 2015.

[4] ASEAN (2014). ASEAN steps up fight against cybercrime and terrorism, ASEAN secretariat news, http://www.asean.org/news/asean-secretariatnews/item/ asean-steps-up-fight-against-cybercrimeand-terrorism/ accessed on 18 March 2015.

[5] ASEAN (2015a). ASEAN engages citizen through social media,ASEANSecretariatnews,http://www.asean.org/ne 
ws/aseansecretariatnew/item/aseanengagecitizenthroug h-social-media/accessed on 17 March 2015.

[6] ASEAN(2015b). ASEAN Intergovernmental commission

onhumanrights(AICHR),http://www.asean.org/commun ities/asean-political-security-

community/category/asean-

intergovernmentalcommissiononhumanrightsaichr/acce ssed on 18 March 2015.

[7] ASEANPOL (2015). Secretariat of ASEANPOL, http://www.aseanapol.org/about-aseanapol/accessed on 18 March 2015.

[8] Carr, J. (2004). Child abuse, child pornography and the internet, UK: $\mathrm{NCH}: 11$

[9] Centre for social and political thought, University of Sussex, www.sussex.ac.uk/cspt/research - accessed 23rd June 2015.

[10] Center for problem-oriented policing (2015). Child pornographyontheinternet,http://www.popcenter.org/pr oblems/child_pornography/print/accessed on 18 March 2015.

[11] Council of Europe (2015). Convention on cybercrime, http://www.coe.int/t/DGHL/cooperation/ economiccrime/cybercrime/default_en.asp/accessed on 18 March 2015.

[12] e-ASEAN (2015). E-ASEAN framework agreement, ASEAN secretariat, http://www.asean.org/news/item/easean-framework-agreement/accessed on 18 March 2015.

[13] Griffiths, M. (2010). Online video gaming: what should educational psychologists know? Educational psychology in practice, 26 (1): $35-40$.

[14] GSMA NTT DOCOMO (2012). Children's use of mobile phones. http://www.gsma.com/ latinamerica/wp-content/uploads/2013/05/GSMAChildrenES English2012WEB.pdf. Accessed on 02 March 2015.

[15] ILO (2014). New avenues for cooperation: Tacking human trafficking in Asia. Available: http://www.eurasiareview.com/05042014-new-avenuesfor-regional-cooperation-tacking-human-trafficking-inasia-analysis/ - Accessed on 22 August, 2014.

[16] International Centre for missing \& exploited children (2013). Child pornography: Model Legislation \& Global Review, http://polis.osce.org/library/f/4060/3771/GOV-USARPT-4060-EN-3771- Accessed on 22nd August 2014.

[17] InternetWorldStats. www.internetworldstats.com - Accessed on 19 August 2014.

[18] JakartaPost(2015). Thai Junta chief defends controversial cyber law plans,

http://www.thejakartapost.com/news/2015/01/27/thaijuntach ief-defends-controversial-cyber-lawplans.html/accessed on 18 March 2015.

[19] Agger, B., (2006). Critical social theories $2^{\text {nd }}$ Edition, Paradigm Publishers, Herndon.
[20] Kingdom of Combodia (2014). Cybercrime Law Draft V.1,http://www.article19.org/data/files/medialibriary/ 37516/DraftLawOnCyberCrime_Englishv1.pdf/accesse d on 18 March 2015.

[21] Malaysian communications and multimedia commission (2015). Prepaid registration - What is the minimum age to register for prepaid SIM card? Malaysian Communications and media commission, http://www.skmm.gov.my/FAQs/Prepaid-Registraion/ What-is-the-minimum-age-to-register-for-prepaidSI.aspx/accessed on 18 March 2015.

[22] McCarthy, T., (1978). The critical theory of Jurgen Habermas, The Massachusetts Institute of Technology.

[23] Kraemer,K.L.andDedrick,J.(1994).Payoffsfrominvestm ent in Information Technology: Lessons from the Asia Pacific Region, World Development, 22 (12): 1921 31.

[24] Mahassni, D. (2015). What is the age of consent in differentcountries?http://www.answers.com/Q/What_is _the_age_of_consent_in_different_countries/accessed on18 March 2015.

[25] Media Development authority of Singapore (2014). Regulatory options to facilitate the adoption of internet parentalcontrols,http://www.mda.gov.sg/RegulationsAn dLicensing/Consultation/

Documents/Consultation\%20Papers/Public\%20consulta tion\%20paper\%20for\%20Internet\%20parental\%20contr ols_21\%20Apr_final.pdf/accessed on 18 March 2015.

[26] Mehra, B., Merkel, C. and Bishop, A.P. (2004). The internet for empowerment of minority and marginalized users, New Media \& Society, 9 (6): 781 - 802.

[27] Melatdouse, H., (2014). Cyber bullying in Malaysia. http://www.cyberbullyinglaws.wordpress.com/ 2010/09/09/cyber-bullying-in-malaysia. Accessed on 22 August 2014.

[28] Michelet. I. (2013). Our children at risk online: The example of Thailand, In: A survey Report, Our children at risk online, The example of Thailand, ECPAT International 2013: 15.

[29] MTV Exit (2014). End exploitation and trafficking. Available: http://mtvexit.org/blog/human-traffickinggoes-cyber-stay-online/ - Accessed on 22 August 2014.

[30] Owens E.W. Behun R.J. Manning J.C and Reid R.C. (2012). The impact of internet pornography on adolescents: A review of the research, Sexual addiction and compulsivity 19 (1-2): 99-122.

[31] Phnom Penh Post. (2012). Violent and child pornography wide spread. Phnom Penh Post 12(2): 5.

[32] Protection of minors (2015). http://www.protection-ofminors.eu/en/cat8.php. Accessed on 2 March 2015.

[33] Rao, M (2015). Regulatory challenges in the emerging internetmediaenvironment,https://www.isoc.org/inet200 0/cdproceedings/8b/8b_1.htm/accessed on 18 March 2015.

[34] Ray, L., (1990). Critical sociology, Edward Elgar Publishing Ltd., England. 
[35] Raylue, N., and Oei, T.P. (2004). Role of culture in gambling and problem gambling, Clinical psychology review, 23 (8): 1087 - 1114.

[36] Rogers, A., (2013). From peer-to-peer networks to cloud computing: How technology is redefining child pornography laws, Pace Law Faculty Publications, $\mathrm{http} / / /$ digitalcommons.pace.edu/cgi/viewcontent.cgi? article $=1961 \&$ context $=$ lawfaculty/accessed on 18 March2015.

[37] Severino, R.C. (2000). Building knowledge societies: ASEAN in the information age, Key note address at the ASEAN regional workshop on building knowledge societies, Kuala Lumpur, $26^{\text {th }}$ January, 2000.

[38] Statista(2015).http://www.statista.com/statistics/193056 /facebook-user-numbers-in-asian-countries. Accessed on 2 March 2015.

[39] Tanielian, A. (2013). Illicit supply and demand: Child sex exploitation in ASEAN. National Taiwan University Law Review, 8 (1): 97 - 140.

[40] The Diplomat (2015). Singapore criminalizes cyber bullyingandstalking,http://thediplomat.com/2014/03/sin gapore-criminalizes-cyber-bullying-andstalking/accessed on 18 March 2015.

[41] The Irrawaddy (2015). Burma to replace controversial electronictransactionslaw,http://www.irrawaddy.org/inv estment/burma-to-replace-controversial-electronictransactions-law.html/accessed on 18 March 2015.

[42] Thai PBS (2014). Computer game addiction alarming amongyouths.Available:http://englishnews.thaipbs.or.th /computer-game-addiction-rises-alarming-amongyouths/ Accessed on 22 August 2014.
[43] Trinidad, A.C. (2005). Child pornography in the Philippines. UP Center for Integrative and Development studies (UP CIDS-PST) and UNICEF: 78 -80 .

[44] UNESCO (2013). Young people and the law in Asia and the Pacific: A review of laws and policies affecting young people's access to sexual and reproductive health andHIVservices,UNESCO,http://unesdoc.unesco.org/i mages/0022/002247/224782E.pdf/accessed on 18 March 2015.

[45] United Nations (2000). United nations convention against transnational organised crime and the protocols thereto, United Nations office on drugs and crime, http://www.unodc.org/unodc/treaties/ CTOC/accessed on 18 March 2015.

[46] Williams, S. Lyons, L. and Ford, M. (2008). It's about bang for your buck, bro: Singaporean men's online conversations about sex in Batam, Indonesia. Asian studies review, 32: 77-97.

[47] Wisdom Society for public opinion Research. (2010). Cyber bullying problems for Thai kids. http://www.nationmultimedia.com/2010/12/02/technolo gy/Cyber-bullying-problek-for-Thai-kids30143640.html Accessed on 22 August 2014.

[48] Yuwono, B. (2014). Measuring the success of ASEAN information \& communication technology masterplan 2015implementation,http://www.itu.int/en/ITUD/Regio nalPresence/AsiaPacific/Documents/Events/2014/Octob er-MIS/ASEAN_Budi_Yuwono.pdf/- accessed on 17 March 2015. 